\title{
Tectonic Subsidence Calculation Based on Seismic Data ${ }^{1}$
}

\author{
Xiaorong Cong ${ }^{1, ~ a}$, Xiaoping $\mathrm{Mao}^{2, \mathrm{~b}}$, Ming $\mathrm{Su}^{1, \mathrm{c}}$, Nengyou $\mathrm{Wu}^{1, \mathrm{~d}}$, Xinghe $\mathrm{Yu}^{2, \mathrm{e}}$, \\ Rui Yang ${ }^{1, f}$ \\ ${ }^{1}$ Guangzhou Institute of Energy Conversion, CAS, Guangzhou, China \\ ${ }^{2}$ University of Geosciences, Beijing 100083, China \\ acongxr@ms.giec.ac.cn, ํmaoxp9@163.com , 'suming@ms.giec.ac.cn, wuny@ms.giec.ac.cn \\ ebillyu@cugb.edu.cn, ${ }^{\mathrm{f}}$ yangrui@ms.giec.ac.cn
}

Keywords: Tectonic subsidence, Basin modeling, Basin analysis, Northern continental slope of South China Sea, Pearl River Mouth Basin

Abstract: The reconstruction of subsidence history of is very important in basin modeling and basin analyses. Tectonic subsidence can reflect the tectonic activity, which was calculated based on burial history. Through quantitative basin modeling research of tectonic subsidence history of deep water area in Pearl River Mouth Basin, tectonic subsidence has been generally characterized by acceleration from north to south and from west to east in the research area since the Late Miocene. Dongsha tectonic event from the end of the Middle Miocene to the end of the Late Miocene and Taiwan tectonic event from the Pliocene to the Early Pleistocene was considered the possible major resons.

\section{Introduction}

Crustal subsidence result in basin formation ${ }^{[1]}$. Analysis of the basin subsidence history is starting from the sequence stratigraphic features and burial history. We use the ultimate maps of the subsidence history, through the parameters (such as: buried depth, geological subsidence, sedimentation rate and tectonic subsidence rate) and the differences of those located in different parts of the structure, combined with subsidence history curve of typical basin and adjacent basins have unified tectonic background, conclusion was drew as follow: the settlement period, the main settlement mechanics mechanism of period, rapid subsidence stage, filling mode and the formation of the basin earth motive mechanism, in addition, Basin differences lifting, tectonic evolution and hydrocarbon generation evolution model can be further studied when the data is enrich enough ${ }^{[1-5]}$.

\section{Study area}

The Pearl River Mouth Basin located in the special interacting position of three continental plates including the Pacific plate, Eurasian Plate and Indian Australian plate, and is a Cenozoic rift basin on the passive continental margin. The Pearl River Mouth Basin deep water area mainly consist of the Zhu II sub-basin in the south, including the Yunkai, Baiyun low uplifts, Kaiping, Shunde, Baiyun and Liwan depressions (Fig. 1) ${ }^{[6,7]}$. 


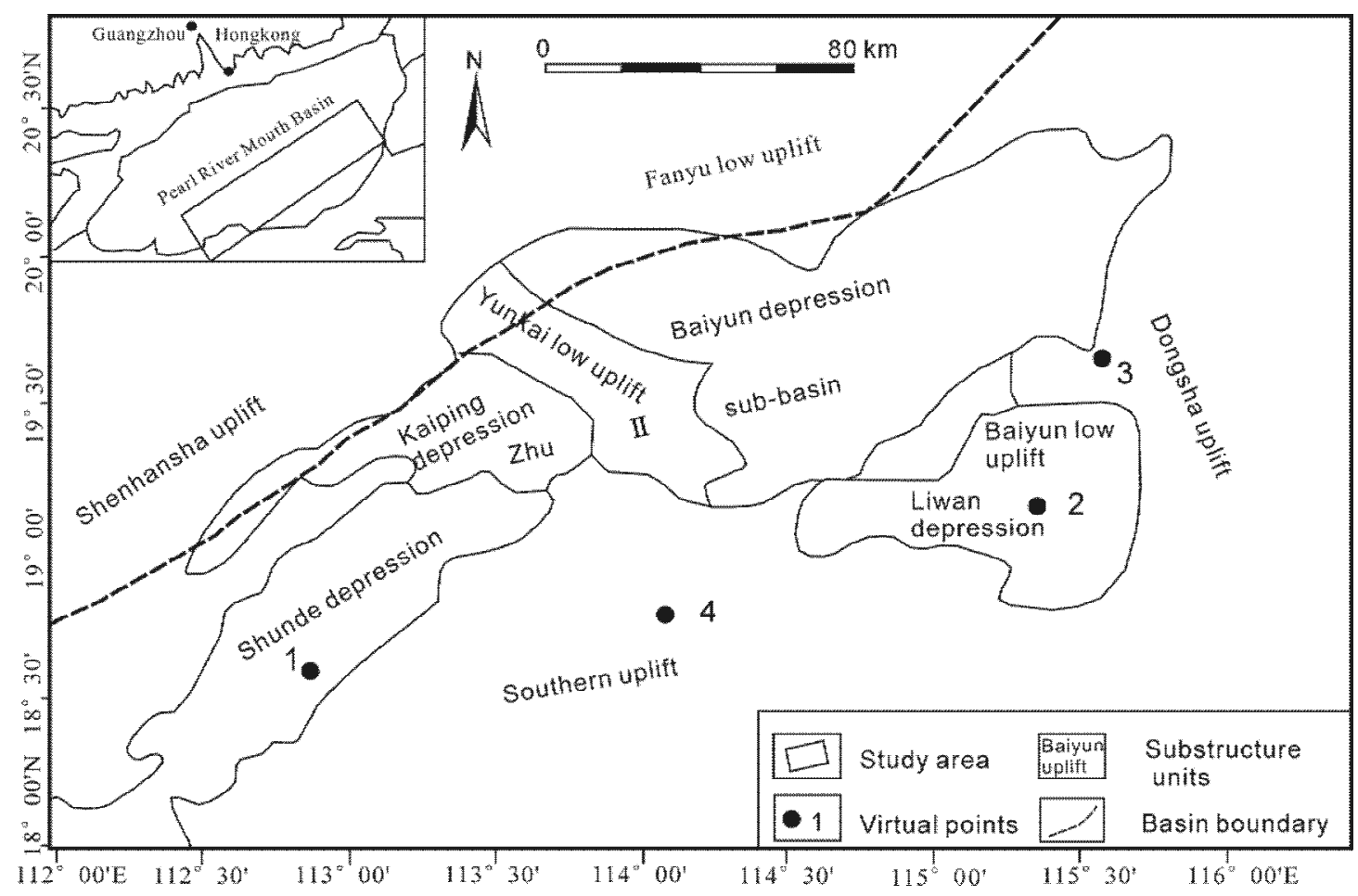

Fig.1. The location and regional tectonic units in the study area ${ }^{[7]}$

\section{Method of heat flow calculation}

Subsidence history has determined the size, geometric shape and structural characteristics of the basin $^{[8]}$. The complete base subsidence range $\left(D_{B}\right)$ for a certain period actually includes two parts: the tectonic subsidence range $\left(D_{T}\right)$ caused by tectogenesis and the load subsidence range $\left(D_{1}\right)$ caused by load balancing. Tectonic subsidence reflects subsidence caused by tectonic movement ${ }^{[9]}$, and plays an important role in the formation mechanism of the basin. Three kinds of revision are needed to calculate tectonic subsidence in the back-stripping method ${ }^{[5,10]}$ : Stratigraphic compaction correlation; paleo-water depth correlation; paleo-ocean level change correlation ${ }^{[11]}$.

Hypothesis $Y_{1}$ and $Y_{2}$ is the depth of a rock strata, when erosion, sediment they correspond respectively with height is $Y_{1}^{\prime}$ and $Y_{2}^{\prime}$, sediment section no change, only the water in pores change, therefore can calculate the sediment thickness on backstripping location ${ }^{[10]}$ :

$Y_{2}^{\prime}-Y_{1}^{\prime}=Y_{2}-Y_{1}+\phi_{0} \frac{e^{-c y_{2}}-e^{-c y_{1}}}{c}+\phi_{0} \frac{e^{-c y_{1}^{\prime}}-e^{-c y_{2}^{\prime}}}{c}$

Where $\phi_{0}$ is lithological surface porosity, $c$ is compaction coefficient of lithology. Using numerical iteration method, we can get the ancient thickness or ancient buried depth of strata in different geological periods. Here, $\phi_{0}$ and $c$ is a mixture of lithology, which was weighted approximate proportion based on the quantitative single layer surface porosity of sandstone and mudstone.

Assumption lithosphere on the top surface of the asthenosphere is composed of a series of floatation column, which was loaded with a balancing process called partial equilibrium or Airy equilibrium $^{[12]}$. After basin subsidence occurred, the water will filled the space, sediment replaced 
the whole or part space for sedimentation over time. Because of the difference of density between water and sediments, load settlement happened in crust (lithosphere), the equilibrium restore. In this paper, the study area is the entire northern slope of the South China Sea, where lithosphere extension largely, effective elastic thickness smally, result in Airy equilibrium, so the load settlement is expressed as:

$D_{L}=\frac{\overline{\rho_{s}}-\rho_{w}}{\rho_{m}-\rho_{w}} H$

Where $H$ is Sediment filling depth with a unit of m, Obtained by burial history; $\rho_{m}, \rho_{c}, \rho_{w}, \overline{\rho_{s}}$ is the average density of crust mantle, water, sediments respectively with a unit of $\mathrm{kg} / \mathrm{m} 3$.

The total subsidence basin $\left(D_{B}\right)$ is the sum of load settlement $\left(D_{L}\right)$ and the tectonic subsidence $\left(D_{T}\right)$, also equal the total thickness of Stratum.

$D_{T}=\frac{\rho_{m}-\overline{\rho_{S}}}{\rho_{m}-\rho_{w}} \cdot H$

During depositing, the sediment interface is at certain depth below the water surface, so the thickness of sediment cannot stand for subsidence depth. We must rectify the paleo-water depth in order to get the accurate tectonic subsidence. After getting the paleo-water depth $\left({ }^{W_{d}}\right)$, we added it to the thickness of sediment, and then obtained the true depth. So the total base subsidence can be expressed as the sum of sediment thickness $(H)$, ancient water depth $\left({ }^{W_{d}}\right)$ and sea level changes $\left(\Delta S_{L}\right)$ theoretically, In which the sea level changes is the difference value of the ancient sea level relative to the current sea level changes, The high water level is positive, Conversely. According to the definition of tectonic subsidence and load settlement above, The following formula can be derived:

$D_{T}=\left(\frac{\rho_{m}-\overline{\rho_{s}}}{\rho_{m}-\rho_{w}} \cdot H-\frac{\rho_{w}}{\rho_{m}-\rho_{w}} \cdot \Delta S_{L}\right)+\left(W_{d}-\Delta S_{L}\right)$

Where previous item in the first brackets represent load correction results of sediment, latter item in the first brackets present load correction results of sea level; The second brackets reflect ancient water depth relative to sea level at present. Because the time span of the study was so short and the sea level changed so little that it could be ignored, $\Delta S_{L}$ was regarded to zero, So that by the following formula:

$D_{T}=\frac{\rho_{m}-\overline{\rho_{s}}}{\rho_{\mathrm{m}}-\rho_{\mathrm{w}}} \cdot H+W_{d}$

This is the formula of calculating tectonic subsidence. We can get it by the burial history. 


\section{Experimental Result Analysis}

Using the above formula, we selected 172 virtual well points in the deep water area of the Pearl River Mouth basin. By following the principles of point-line-plane research process of reasoning as well as the theory and calculation of tectonic subsidence, we simulate and calculate the tectonic subsidence and tectonic subsidence rate of the virtual well points on the basis of parameters like the sandy ratio, porosity-depth relationships.

These points are taken for example: 1 in the Shunde depression, 2 in the Baiyun depression and 4 in the South uplift, and the evolution of tectonic subsidence is researched(Fig2).
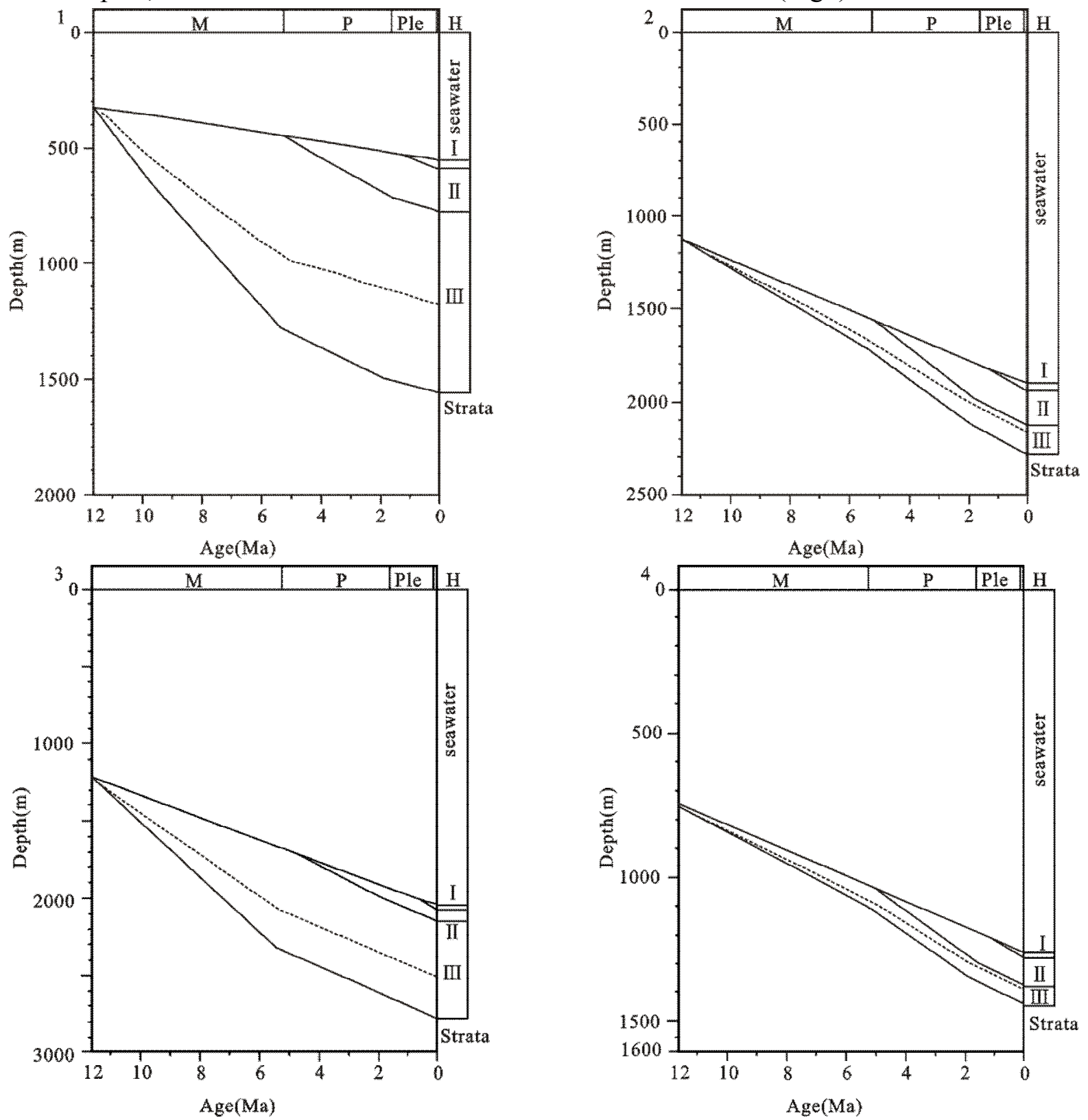

Fig.2. The single point history and tectonic subsidence history curve in the Pearl River Mouth basin(the dashed line indicates the tectonic subsidence curve, its slope indicates the tectonic subsidence rate).

As is show in fig.2, Each region has its own unique burial history and tectonic subsidence history, but in general they show a steady subsidence. 


\section{Conclusion}

In this paper, we proposed a derived method, Tectonic subsidence was calculated. Through generating pseudo-logging data, establishing initial model, logging-seismic marking and wavelet extracting and final tectonic subsidence value, this solution can deduce more precise and reasonable basin model to calculate the tectonic subsidence. Thereby, equilibrium model is very important for the calculation of tectonic subsidence, and make it even close to the actual situation underground, that is very helpful in geological exploration.

\section{Acknowledgements}

This work was financially supported by the National Natural Science Foundation of China (No.41206047), Key Research Program of the Chinese Academy of Sciences (No. KGZD-EW-301), and CAS/SAFEA International Partnership Program for Creative Research Teams.

\section{References}

[1]. Lu kezheng. : Analysis of petroliferous basin. China University of Petroleum press. 2003: 285-288

[2]. Ben A Z, Uyeda S. : The evolution of the China basin and the Mesozoic pale geography of Borneo. Earth Planet. 78(1973): 365-376.

[3]. CLIFT P D, Sun Zhen. : The sedimentary and tectonic evolution of the Yinggehai \$ Song Hong basin and the southern Hainan margin, South China Sea: Implications for Tibetan uplift and monsoon intensification. Geophysics Roes, 111(2006): 1-28.

[4]. Taylor B, Hayes D E. : The tectonics and geological evolution of South China Sea Basin. In: D. E. Hayes (ed) The tectonics and geological evolution of Southeast Asian Seas and islands. American Geophysical union Monography, 23(1980): 89-104.

[5]. Lin Changsong and Zhang Yanmei. : Simulation of basin subsidence history. Basin analysis of the northern south China sea continental margin and hydrocarbon accumulation. Beijing: Science Press, (1997): 75-86.

[6]. Li Yun, Zheng Rongcai, Yang Baoquan, et al. : Deep-water depositional features of Miocene Zhujiang formation in Baiyun Sag, Pearl River Mouth Basin. Acta Geologica Sinica(English Edition), 87(1)(2013): 197-210.

[7]. Chen Changmin, Shi Hesheng, Xu Shice et al. : Pearl river mouth Basin(eastern) formation conditions of Tertiary reservoir. Beijing Science Press, (2003): 7-9.

[8]. Guo Qiulin, Mi Shiyun, Shi Guangren et al. : Principle method for natural gas hydrate storage and transportation processes. Energy Conversion and Management, (1998): 39-44.

[9]. Royden L, Keen C E.: Rifting processes and thermal evolution of the continental margin of eastern Canada determined from subsidence curves. Earth Planet. 51(1980): 343-361.

[10]. Allen, P.A. and Allen, J.R.: Basin analysis: principles and applications. London: British Petroleum Company, (1990): 1-451.

[11]. Lu Lin, Wang Qihao and Huang Jianjun.: Structural evolvement history of Weixinan and Haizhong depression in Beibuwan basin during Cenozoic Era. Offshore oil, 27(1)2007: 25-29. 
[12]. Athy L F.: Density Porosity and compaction of sedimentary rocks. AAPG Bulletin, 14(1)(1930): 1-24. 